\title{
SEPSIS IN PUERPERIUM, BUT NOT PUERPERAL SEPSIS
}

Deepak Srinivas Ratakonda ${ }^{1}$, Tirupathipannayam Ananthakrishnan Vidya², Ruckmani Venkatraman ${ }^{3}$,

Sarfaraz Ahmed Tharaganar Abubacker ${ }^{4}$, Krishna Kumar Venkatachalam ${ }^{5}$

1 Postgraduate Student, Department of General Medicine, SRM Medical College Hospital and Research Centre.

${ }^{2}$ Associate Professor, Department of General Medicine, SRM Medical College Hospital and Research Centre.

3Professor, Department of General Medicine, SRM Medical College Hospital and Research Centre.

${ }^{4}$ Assistant Professor, Department of General Medicine, SRM Medical College Hospital and Research Centre.

${ }^{5}$ Assistant Professor, Department of General Medicine, SRM Medical College Hospital and Research Centre.

HOW TO CITE THIS ARTICLE: Ratakonda DS, Vidya TA, Venkatraman R, et al. Sepsis in puerperium, but not puerperal sepsis. J. Evolution Med. Dent. Sci. 2017;6(93):6794-6795, DOI: 10.14260/jemds/2017/1470

\section{PRESENTATION OF CASE}

A 24-year-old female, a primiparous mother who had delivered 15 days ago by a labour naturale with episiotomy, presented with a history of low-grade fever for two days and altered sensorium for one day. She had a history of severe pain in the lower back for the last two days which was a localised, dull, boring type of pain that radiated to both lower limbs. The pain was so severe that the patient was unable to walk. There was no history of chest pain, palpitations, breathlessness, pedal oedema, abdominal distension, headache, vomiting, giddiness or diplopia. She had no significant comorbidities.

She was drowsy, disoriented and febrile. No eschars or purpura were noted. Her vitals were stable with a BP of $120 / 60 \mathrm{mmHg}$ and a pulse rate of $110 / \mathrm{min}$. Examination of cardiovascular system and respiratory system was normal. Her abdomen was soft, non-tender, and the uterus was firm and contracted. Neurological examination did not show any focal deficits and she had no meningeal signs or neck stiffness. Fundus examination showed grade III hypertensive retinopathy with no evidence of papilloedema. Per vaginal examination showed an infected episiotomy wound with discharge and unhealthy granulation tissue.

A complete haemogram revealed neutrophilic leucocytosis with a total count of $28,400 / \mathrm{mm}^{3}$, and a microcytic hypochromic anaemia with a haemoglobin of 8.6 $\mathrm{g} / \mathrm{dL}$. Coagulation profile and renal and liver function tests were normal. Rheumatological workup with ESR, CRP, RA, anti-CCP, ANA and anti-dsDNA was negative. Ultrasound of the abdomen showed a bulky uterus and also revealed a bilateral pleural effusion. CT brain showed multiple infarcts. An MRI of the brain with MRA and MRV was performed and this showed multiple acute infarcts in bilateral cerebral and cerebellar hemispheres. A transoesophageal echocardiography showed a $1.0 \times 2.1 \mathrm{~mm}$ mobile mass attached to the anterior mitral leaflet, suggestive of a left atrial clot with a cardioembolic stroke. Three blood cultures were drawn to rule out infective endocarditis, and they were all sterile.

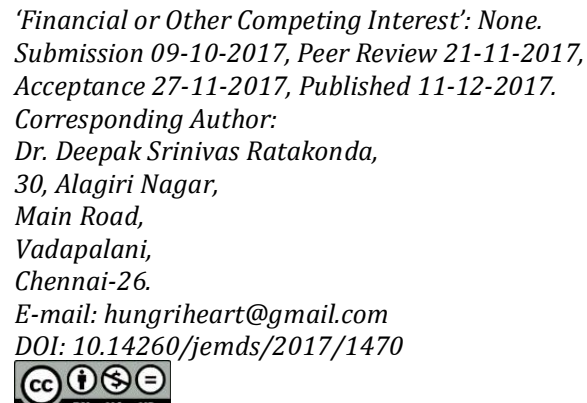

\section{DIFFERENTIAL DIAGNOSES}

- Puerperal sepsis with an infected episiotomy wound.

- Infective endocarditis.

- Left atrial myxoma.

- Left atrial clot.

\section{CLINICAL DIAGNOSIS}

Puerperal sepsis with an infected episiotomy wound.

\section{DISCUSSION OF MANAGEMENT}

The patient was started on heparin, clopidogrel and atorvastatin, and was given broad-spectrum antibiotics. Her sensorium gradually improved and she eventually made a complete recovery. The left atrial appendage is the most common site for cardiac thrombus. It is anatomically attached to the left inferior portion of the left atrium and consists of muscular trabeculae. The left atrial appendage does not contribute, to a large degree, to overall cardiac output.

Thrombus within the left atrium (LA) is well visualised with transoesophageal echocardiography (TEE), ${ }^{1}$ as thoracic views are not adequate to visualise the left atrial appendage. LA thrombus is usually detected in association with atrial arrhythmias, but is uncommon in the presence of sinus rhythm (SR). ${ }^{2,3}$

Transoesophageal echocardiographic finding includes direct visualisation of a mobile echodensity within the appendage. The echodensity should move independent of the walls of the atrium, which helps to distinguish artefact or trabeculae from thrombus. Pulse wave Doppler can be used in the left atrial appendage to determine the flow velocity. A velocity of $<0.4 \mathrm{~m} / \mathrm{s}$ indicates a higher risk, in general of thromboembolism. ${ }^{4}$ Cardiac CT can be used as well.

During atrial fibrillation and atrial flutter, the left atrial appendage loses contractility. This results in decreased flow velocities and rouleaux formation of red blood cells, which is seen as "spontaneous echo contrast" on echocardiography.

If a thrombus in the left atrial appendage embolises, stroke can occur. Embolism to the lower extremities, kidney, spleen or mesenteric vessels can occur as well. ${ }^{5}$

\section{FINAL DIAGNOSIS}

Left atrial clot presenting with sepsis and cardioembolic stroke.

\section{CONCLUSION}

This case highlights the fact that not all psychosis in the puerperium is puerperal psychosis, and not all sepsis in the puerperium is puerperal sepsis. Even in patients who present with apparently obvious gynaecological problems, medical problems should be kept in mind. 


\section{REFERENCES}

[1] Manning WJ, Weintraub RM, Waksmonski CA, et al. Accuracy of transesophageal echocardiography for identifying left atrial thrombi: a prospective, intraoperative study. Ann Intern Med 1995;123(11):817-22.

[2] Jaber WA, Prior DL, Thamilarasan M, et al. Efficacy of anticoagulation in resolving left atrial and left atrial appendage thrombi: a transesophageal echocardiographic study. Am Heart J 2000;140(1):1506.
[3] Omran H, Rang B, Schmidt H, et al. Incidence of left atrial thrombi in patients in sinus rhythm and with a recent neurologic defect. Am Heart J 2000;140(4):658-62.

[4] Jacobi A, Godelman A. Left atrial thrombus. Cardiac Imaging 2014:327.

[5] Kasper DL, Fauci AS, Hauser SL, et al. Harrison's principles of internal medicine. Vol 1. 19th edn. New York: McGraw-Hill Education, 2015. 